\title{
Päpstliche und kaiserliche Privilegien für den Deutschen Orden in Preußen zwischen Recht und Erinnerung. Einführung ins Thema
}

\section{Papal and imperial privileges for the Teutonic Order in Prussia between law and memory. An thematic introduction}

Přemysl Bar / bar@phil.muni.cz

Ústav pomocných věd historických a archivnictví FF MU

\begin{abstract}
The importance of papal and imperial privileges for the Teutonic Order increased in the conflictual period between the Order and Polonia/Lithuania in the years following 1386, when polish lawyers began to doubt all its privileges on a general base. It's nevertheless surprising that these privileges don't almost show in the medieval historiography of the Order. It's therefore necessary to stimulate further research dedicated to the cartularies and the privilege confirmations under their legal and memorial aspects.
\end{abstract}

\section{Keywords}

privileges, Teutonic order, Polonia-Lithuania, Peter of Dusburg, historiography of the order, cartularies, charter inserts

Der Aufsatz entstand in Rahmen des Projekts "Operational Programme Research, Development and Education: Postdoc@MUNI (Project Identification: CZ.02.2.69/0.0/0.0/16_027/000836)". Für sprachliche Korrekturen bzw. wertvolle Anregungen bin ich Petra Heinicker und Adam Szweda zu großem Dank verpflichtet. 
Die päpstlichen und kaiserlichen Privilegien für den Deutschen Orden spielen für dessen Rechtsstellung sowie für seine gesellschaftliche und politische Entwicklung eine kaum zu überschätzende Rolle. In der Forschung jedoch wird diese komplexe Problematik meist einseitig behandelt. Im Vordergrund nämlich stehen die rechtlichen und politischen Aspekte.

In der Literatur wird stets betont, dass der Hochmeister und der Orden von Anfang an, vornehmlich aber in der späten Stauferzeit, in die Auseinandersetzung zwischen Papsttum und Kaisertum verwickelt wurden. Man kann wohl sagen, dass die gesamte Entwicklung des Ordens im Mittelalter (bis zur Auflösung des preußischen Ordenszweigs 1525) wesentlich durch die nicht immer eindeutige Stellung des Ordens gegenüber den zwei abendländischen Universalmächten geprägt wurde. ${ }^{1}$ Dies spiegelt sich unter anderem in den Friedensverträgen zwischen dem Orden und Polen bzw. Polen-Litauen wider, wo Papst oder Kaiser entweder in die Abmachungen einbezogen oder aber - ganz im Gegenteil - von jenen ausgeschlossen wurden. ${ }^{2}$

Der Inhalt der päpstlichen und kaiserlichen Privilegien ermöglicht auch unterschiedliche Interpretationen in Bezug auf die Rechtsstellung des Ordens im Gefüge des deutsch-römischen Reichs. Die ältere Forschung konzentrierte sich auf die verfassungsrechtliche Bedeutung des dem Hochmeister gewährten Reichsfürstentitels und die Autorität, mit welcher der König bzw. Kaiser dem Orden Privilegien erteilt hatte. ${ }^{3}$ Später wurde der Schwerpunkt der Forschung auf die Frage der Lehnsexemtion der Ordensbrüder, denen jede Eidesleistung untersagt worden sein soll, verlegt. ${ }^{4}$ Trotzdem bleibt die Stellung des Hochmeisters bzw. des Ordens gegenüber dem Reich weiterhin unklar. $^{5} \mathrm{Zu}$ dieser Unklarheit trägt auch die pragmatische Einstellung verschiedener

1 Lubenow, Herwig: Kaisertum und Papsttum im Widerstreit bei der Gründung des Deutschordensstaates in Preußen. Geschichte in Wissenschaft und Unterricht 23, 1972, S. 193-211, der zeigen will, dass der Papst eine im Vergleich zum Kaiser hervorragendere und erfolgreichere Rolle beim Aufbau der Ordensherrschaft in Preußen gespielt habe; vgl. Arnold, Udo: Der Deutsche Orden zwischen Kaiser und Papst im 13. Jahrhundert. In: Die Ritterorden zwischen geistlicher und weltlicher Macht im Mittelalter. Hg. von Zenon Hubert Nowak. Ordines militares. Colloquia Torunensia Historica 5. Toruń 1990, S. 57-70; Beuttel, Jan-Erik: Der Generalprokurator des Deutschen Ordens an der römischen Kurie. Amt, Funktion, personelles Umfeld und Finanzierung. Quellen und Studien zur Geschichte des Deutschen Ordens (= QSGDO) 55. Marburg 1999, S. 19-44; vgl. Jähnig, Bernhart: Der Deutsche Orden und die livländischen Bischöfe im Spannungsfeld von Kaiser und Papst. Nordost-Archiv. Zeitschrift für Regionalgeschichte N.F. 7, 1998, S. 47-63 (Neudruck in ders.: Vorträge und Forschungen zur Geschichte des Preußenlandes und des Deutschen Ordens im Mittelalter. Ausgewählte Beiträge zum 70. Geburtstag am 7. Oktober 2011. Hg. von Hans-Jürgen Kämpfert - Barbara Kämpfert. Münster 2011, S. 442-456), der die päpstlichen und kaiserlichen Eingriffe in livländische Verhältnisse klar darlegt.

2 Auf die Veränderung der Rolle, die entweder Papst oder Kaiser in den jeweiligen Verträgen spielten, weist Neitmann, Klaus: Papst und Kaiser in den Staatsverträgen des Deutschen Ordens in Preussen 1230-1466. Archiv für Diplomatik, Schriftgeschichte, Siegel- und Wappenkunde 33, 1987, S. 293-321 hin.

3 Werminghoff, Alfred: Die Hochmeister des Deutschen Ordens und das Reich bis zum Jahre 1525. Historische Zeitschrift 110, 1913, S. 473-518.

4 Stengel, Edmund Ernst: Hochmeister und Reich. Die Grundlagen der staatsrechtlichen Stellung des Deutschordenslandes. Zeitschrift der Savigny-Stiftung für Rechtsgeschichte. Germanistische Abteilung 58, 1938, S. 178-213; vgl. Matison, Ingrid: Die Lehnsexemtion des Deutschen Orden und dessen staatsrechtliche Stellung in Preußen. Deutsches Archiv 21, 1965, S. 194-248.

5 Vgl. Israel, Ottokar: Das Verhältnis des Hochmeisters des Deutschen Ordens zum Reich im 15. Jahrhundert. Mar- 
deutsch-römischer Kaiser ( siehe Friedrich II. ${ }^{6}$ und Ludwig IV. von Bayern ${ }^{7}$ ) bei, die eher dazu tendierten, bestimmte Ordens-Balleien oder Ordenshäuser in ihren eigenen Herrschaftsgebieten (zumeist im Reich) als den Ordensstaat in Preußen förderten, was sich besonders unter den Herrschern aus der luxemburgischen Dynastie zeigt. ${ }^{8}$

Mit der Problematik der Ordensprivilegien ist ebenfalls die Rechtsgrundlage der Ordensherrschaft in Preußen untrennbar verflochten, was sich freilich häufig auf paläographische, diplomatische und rechtsinhaltliche Analysen der Goldbulle von Rimini Kaiser Friedrichs II. beschränkt, die im März 1226 ausgestellt worden sein soll. ${ }^{9}$ Trotzdem sind

burg 1952; Boockmann, Hartmut: Die Vertretung des Deutschen Ordens auf den spätmittelalterlichen Reichstagen. In: Nord und Süd in der deutschen Geschichte des Mittelalters. Akten des Kolloquiums veranstaltet zu Ehren von Karl Jordan, 1907-1984, Kiel, 15.-16. Mai 1987. Hg. von Werner Paravicini. Sigmaringen 1990, S. 97-108 und Heckmann, Marie-Luise: Der deutsche Orden und die „Goldene Bulle“ Kaiser Karls IV. Mit einer Vorbemerkung zur Herkunft der Quaternionen. Jahrbuch für die Geschichte Mittel- und Ostdeutschlands 52, 2006, S. 173-226.

6 Von der umfangreichen Literatur sei hier nur erwähnt: Engels, Odilo: Kaiser Friedrich II. und der Deutsche Orden. In: Der Deutsche Orden in Europa. Hg. von Udo Arnold. Schriften zur staufischen Geschichte und Kunst 23. Göppingen 2004, S. 115-127; Kluger, Helmuth: Hochmeister Hermann von Salza und Kaiser Friedrich II. Ein Beitrag zur Frühgeschichte des Deutschen Ordens. Marburg 1987; Wojtecki, Dieter: Der Deutsche Orden unter Friedrich II. In: Probleme um Friedrich II. Hg. von Josef Fleckenstein. Vorträge und Forschungen 16. Sigmaringen 1974, S. 187-224.

7 Hein, Max: Die Verleihung Litauens an den Deutschen Orden durch Kaiser Ludwig den Bayern im Jahre 1337. Altpreußische Forschungen 19, 1942, S. 36-54, der vor allem mit der Vorgeschichte der Urkunden sich befasst; Werminghoff, Albert: Die Urkunden Ludwigs des Bayern für den Hochmeister des Deutschen Ordens vom Jahre 1337. Archiv für Urkundenforschung 5, 1914, S. 21-40; von Pflugk-Hartung, Julius: Der Johanniterund der Deutsche Orden im Kampfe Ludwigs des Bayern mit der Kurie. Leipzig 1900.

8 Die Beziehung Kaiser Karls IV. zu den Ordenszweigen im Reich, in Preußen und in Livland kann gleichfalls als pragmatisch bezeichnet werden, weil sie durch seine Hausmachtpolitik bestimmt wurde, siehe Jähnig, Bernhart: Der Deutsche Orden und Karl IV. Blätter für deutsche Landesgeschichte 114, 1978, S. 103-149 (Neudruck in ders.: Vorträge und Forschungen, S. 16-66); Arnold, Udo: Preußen, Böhmen und das Reich. Karl IV. und der Deutsche Orden. In: Kaiser Karl IV. Staatsmann und Mäzen. Hg. von F. Seibt aus Anlaß der Ausstellungen Nürnberg und Köln 1978/79 in Zusammenarbeit mit dem Bayerischen Nationalmuseum und dem Adalbert Stifter-Verein München. München 1978, S. 167-173, 450-452; Hellmann, Manfred: Karl IV. und der Deutsche Orden in den Jahren 1346-1360. Folia diplomatica 1, 1971, S. 105-112 und Conrad, Klaus: Litauen, der Deutsche Orden und Karl IV. 1352-1360. Zeitschrift für Ostforschung 21, 1972, S. 20-41, der versucht zu verdeutlichen, dass der Versuch zur Bekehrung der litauischen Fürsten im Jahr 1358 auf eine Initiative Kaiser Karls IV. zurückging; vgl. dazu Grundmann, Herbert: Das Schreiben Kaiser Karls IV. an die heidnischen Litauer-Fürsten 1358. Folia diplomatica 1, 1971, S. 89-103. Eine in noch höherem Maße pragmatische Politik gegenüber dem Orden betrieb Kaiser Sigismund, siehe Hoensch, Jörg K.: König/Kaiser Sigismund, der Deutsche Orden und Polen-Litauen. Stationen einer problembeladenen Beziehung. Zeitschrift für Ostforschung 46, 1997, S. 1-44; vgl. Pósán, László: Sigismund und der Deutsche Orden. In: Das Zeitalter König Sigmunds in Ungarn und im Deutschen Reich. Hg. von Tilmann Schmidt und Péter Gunst. Debrecen 2000, S. 73-8, dessen These, dass die Partnerschaft zwischen Sigismund und dem Orden „für beide Seiten ein dauerhaftes, berechenbares und sicheres Element in ihrer Politik“ bedeutete, sehr umstritten ist.

9 Die im 19. Jahrhundert begonnene und bis heute nicht zu Ende geführte Debatte über diese Urkunde gründet in ihrer unklaren Überlieferung, siehe Lohmeyer, Karl: Kaiser Friedrichs II. Verleihungsurkunde über Preußen und Kulmland für den Deutschen Orden zum ersten Male nach dem Original veröffentlicht. Zeitschrift für preussische Geschichte und Landeskunde 6, 1869, S. 629-635; Perlbach, Max: Preussisch-polnische Studien zur Geschichte des Mittelalters. Heft I. Zur Kritik der ältesten preussischen Urkunden. Halle 1886, S. 45-56; Grumblat, Hans: Über einige Urkunden Friedrichs II. für den Deutschen Orden. Mitteilungen des Instituts für Österreichische Geschichtsforschung 29, 1908, S. 385-422, hier S. 385-408. Die Echtheit der Urkunde 
die Privilegien für den Deutschen Orden als Gesamtheit noch nicht erforscht worden, obwohl eine nach wie vor gültige Edition dieser Privilegien seit 1869 vorliegt. ${ }^{10}$ Das Vorhandensein dieser Edition hat an den Forschungsdesiderata nichts Grundlegendes geändert. Der Grund dürfte in der kaum überschaubaren Überlieferungslage liegen. Päpstliche wie kaiserliche Privilegien sind jeweils in großer Menge in verschiedenen Archiven und Bibliotheken und in unterschiedlichen Überlieferungsformen erhalten. Werden in der Ordensforschung einzelne Stücke analysiert, dann werden in der Regel einseitig lediglich rechtliche Aspekte der Privilegien akzentuiert. Memoriale Aspekte der jeweiligen Urkunden hingegen treten dabei völlig in den Hintergrund.

Die Erforschung des Verhältnisses zwischen rechtlichen und memorialen Aspekten der Ordenprivilegien steht aus mehreren Gründen noch am Anfang. Abgesehen von den Fragen, die auf die rechtliche Bedeutung und das historische Gedächtnis der jeweiligen Privilegien abzielen, müssen zunächst die damit verknüpften grundlegenden Probleme gelöst werden. So stellen z. B. allein die Kriterien, nach welchen die Privilegien geordnet werden sollen, eine Schwierigkeit dar. Eine Ordnung nach Empfängern - z. B. Hochmeister und der gesamte Orden, bestimmte Provinzen (Balleien) und einzelne Komtureien - liegt zwar nahe, ist aber aufgrund der Überlieferung manchmal nicht durchführbar. Schon eine lediglich flüchtige Durchsicht einiger Kopialbücher macht schnell deutlich, dass einstweilen eine präzise Kategorisierung derjenigen Privilegien, die einem Ordenshaus, einer Ordensballei, einem Ordenszweig (Reich, Preußen und Livland) oder dem gesamten Orden verschiedene Rechte und Freiheiten gewährten,

wurde durch Kętrzyński, Wojciech: Der Deutsche Orden und Konrad von Masowien 1225-1235. Eine Studie. Lemberg 1904, S. 128-137 angezweifelt, aber seine Begründung durch Perlbach, M.: Hermann von Salza und der deutsche Orden im jüngsten polnischen Gericht. Zeitschrift des Westpreussischen Geschichtsvereins 48, 1905, S. 217-225 abgelehnt. Auf Zwiefeln an der Echtheit beharrte Gerard, Labuda: Über die Urkunden zur Gründung des Deutschen Ordens im Kulmerlande und in Preussen in den Jahren 1226-1234. In: ders.: Studia krytyczne o początkach Zakonu krzyżackiego w Prusach i na Pomorzu. Pisma wybrane. Poznań 2007, S. 189-211 und ders.: Über die angeblichen und vermuteten Fälschungen des Deutschen Ordens in Preußen. In: ebd., S. 249-269. Zinsmaier, Paul: Die Reichskanzlei unter Friedrich II. In: Probleme um Friedrich II. Hg. von Josef Fleckenstein. Vorträge und Forschungen 16. Sigmaringen 1974, S. 147-148 kam zu dem Schluss, dass die Goldbulle erst um die Mitte der dreißiger Jahren des 13. Jahrhunderts entstanden sein kann. Seine Argumentation wurde zunächst nicht akzeptiert: Arnold, Udo: Probleme um Friedrich II. Der Deutsche Orden und die Goldbulle von Rimini 1226. Preußenland 14, 1976, S. 44-48; Hubatsch, Walther: Zur Echtheitsfrage der Goldbulle von Rimini Kaiser Friedrichs II. für den Deutschen Orden 1226. In: Von Akkon bis Wien. Studien zur Deutschordensgeschichte vom 13. bis zum 20. Jahrhundert. Festschrift zum 90. Geburtstag von Althochmeister P. Dr. Marian Tumler O.T. am 21. Oktober 1977. Hg. von Udo Arnold. QSGDO 20. Marburg 1978, S. 1-5; Löwener, Marc: Bemerkungen zum Text der Rimini-Bulle Kaiser Friedrichs II. für den Deutschen Orden vom März 1226. In: Beiträge zur Geschichte des Deutschen Ordens. Bd. 2. Hg. von Udo Arnold. QSGDO 49. Marburg 1993, S. 51-67. Dank der weiteren Untersuchungen von Tomasz Jasiński setzt die heutige Forschung übereinstimmend die Entstehung der Goldbulle von Rimini im Jahre 1235 an: Jasiński, Tomasz: Die Goldene Bulle von Rimini Kaiser Friedrichs II. für den Deutschen Orden. In: ders.: Kruschwitz, Rimini und die Grundlagen des preussischen Ordenslandes: Urkundenstudien zur Frühzeit des Deutschen Ordens im Ostseeraum. QSGDO 63. Marburg 2008, S. 71-130 und ders.: Forschungen zur Goldenen Bulle von Rimini ab 1993 - ein Nachtrag. In: ebd., S. 131-153; Jähnig, Bernhart: Kaiser Friedrich II. und seine Bedeutung für den Deutschen Orden. In: Ostdeutsche Gedenktage 2000. Persönlichkeiten und Historische Ereignisse. Bonn 1999, S. 301-311.

10 Tabulae ordinis Theutonici. Ex tabularii regii Berolinensis codice potissimum edidit Ernestus Strehlke. Berolini 1869. 
aufgrund unserer heutigen Kenntnisse nicht durchführbar ist. Deswegen erscheint die weitere Erforschung der Überlieferungslage von großer Bedeutung.

Nicht zuletzt aus den erwähnten Gründen müssen die folgenden Überlegungen als eine Einführung in die Problematik betrachtet werden, die jedoch mögliche weitere Forschungsperspektiven aufzeigen kann. Aus der bisherigen Bearbeitung der vorhandenen Quellen haben sich drei maßgebliche Blickwinkel herauskristallisiert, aus denen sie betrachtet werden können: 1) die steigende Bedeutung der Privilegien während des Rechtstreits zwischen dem Orden und Polen-Litauen; 2) die Rolle der Privilegien in der Ordensgeschichtsschreibung; und 3) die Privilegien in den spätmittelalterlichen Kopialbüchern.

\section{Die Privilegien im Rechtsstreit zwischen dem Deutschen Orden in Preußen und Polen-Litauen}

Die Herrschaftsbildung des Ordens in Preußen verlief im Verhältnis zu den Nachbarländern zu keiner Zeit konfliktfrei. Es scheint jedoch, als hätten die Privilegien in den Rechtsverfahren, die zwischen dem Orden und Polen seit Anfang des 14. Jahrhunderts geführt wurden, zunächst - vor allem aus polnischer Sicht - keine wesentliche Rolle gespielt. Stattdessen wurde besonderer Nachdruck auf die in den Prozessakten enthaltenen Zeugenaussagen gelegt. ${ }^{11}$ Die Situation änderte sich wesentlich nach 1386, als es zu einem politischen Bündnis zwischen Polen und Litauen kam, weil von da an, die Rechtsgrundlage für die bloße Existenz des Ordens in Frage gestellt wurde. ${ }^{12}$ In den darauffolgenden Verhandlungen, die entweder unmittelbar zwischen beiden Streitparteien vor einem Schiedsrichter oder auf einem Konzil geführt wurden, gewannen die

11 Die Zeugenaussagen aus dem Warschauer Prozess von 1339 (Lites ac res gestae inter Polonos Ordinemque Cruciferorum = Spory i sprawy pomiędzy Polakami a Zakonem Krzyżackim. Tom I. Hg. von Ignacy Zakrzewski. Poznań 1890², S. 65-142; weiter siehe Chłopocka, Helena: Świadkowie procesu polsko-krzyżackiego w 1339 r. Pamiętnik Biblioteki Kórnickiej 23, 1993, S. 23-35 und dies.: Procesy Polski z Zakonem Krzyżackim w XIV wieku. Studium źródtoznawcze. Poznań 1967) werden in der Forschung als Quelle zur Identitätsbildung und Konstruktion der Vergangenheit im spätmittelalterlichen Polen hervorgehoben, siehe von GüttnerSporzyński, Darius: Memorialisation and Historical Awarness - Witness Testimonies in Trials Between Poland and the Teutonic Order in the Fourteenth and Fifteenth Centuries. In: Arguments and Counter-Arguments. The Political Thought of the 14th-15th Centuries During the Polish-Teutonic Trials and Disputes. Hg. von Wiesław Sieradzan. Toruń 2012, S. 55-67; Sieradzan, Wiesław: Świadomość historyczna świadków w procesach polsko-krzyżackich w XIV-XV wieku. Toruń 1993; Gawlas, Sławomir: „Verus heres. “ Z badań nad świadomościa polityczna obozu Wtadystawa Eokietka w poczatku XVI w. Kwartalnik Historyczny 95/1, 1992, S. 77-104. Dagegen heben Szweda, Adam - Adamska, Anna: Notariusz przy pracy. Akcja transumowania dokumentów krzyżackich jesienia 1421 roku. In: Memoria viva. Studia historyczne poświęcone pamięci Izabeli Skierskiej (1967-2014). Warszawa - Poznań 2015, S. 490-491, Anm. 14 das ungewöhnliche Geschick hervor, mit dem der Orden mit seinen Privilegien bei dem Gerichtsverfahren schon im Jahr 1339 umging.

12 Das Jahr 1386 wird in der Forschung als Wendepunkt in den preußisch-polnisch-litauischen Beziehungen immer wieder hervorgehoben, siehe z. B. Boockmann, Hartmut: Johannes Falkenberg, der Deutsche Orden und die polnische Politik. Untersuchungen zur politischen Theorie des späteren Mittelalters. Mit einem Anhang: Die Satira des Johannes Falkenberg. Göttingen 1975, S. 53-58 und Gersdorf, Harro: Der Deutsche Orden im Zeitalter der polnisch-litauischen Union. Die Amtszeit des Hochmeisters Konrad Zöllner von Rotenstein (1382-1390). Marburg an der Lahn 1957. 
päpstlichen und kaiserlichen Privilegien für den Orden zunehmend an Bedeutung. ${ }^{13}$ Die Zusammensetzung der Gruppe relevanter Urkunden, unter denen sich mitunter auch solche anderer Herrscher befanden, wechselte und wurde unter anderem durch die sich wandelnde politische Situation bedingt. Ihren Kern bildeten jedoch immer die Privilegien von Päpsten und Kaisern oder Königen aus dem 13. bzw. 14. Jahrhundert.

Im März 1389 legten die Gesandten des Hochmeisters denjenigen des Königs von Polen einige Urkunden sowohl des litauischen Königs Mindaugas als auch der Päpste und Kaiser vor, welche die Ansprüche des Ordens auf dessen Oberhoheit über das litauische Land geltend machen. ${ }^{14}$ Daraufhin sollen die polnischen Gesandten erklärt haben, dass der Orden den Krieg mit dem König von Polen in Wahrheit nur wegen der Eroberung des litauischen Landes und nicht wegen der Verbreitung des christlichen Glaubens geführt habe. ${ }^{15}$

Eine gute Gelegenheit, die Ordensprivilegien vorzulegen und zu verfechten, ergab sich im Laufe des Schiedsverfahrens, das der Jurist Benedikt von Makra als Subarbiter im Auftrag König Sigismunds in Polen und Litauen im Jahr 1413 führte. ${ }^{16}$ Am 25. Januar in Kaunas legte der Ordensprokurator Kaspar Schuwenpflug ein Bündel von Urkunden vor (oblat. die Mercurii XXV mensis Ianuarii per procuratorem Ordinis anno Domini millesimo

13 Dies zeigt sich vor allem in den Schiedsverfahren vor König Wenzel IV. (Jóźwiak, Sławomir - Kwiatkowski, Krzysztof - Szweda, Adam - Szybkowski, Sobiesław: Wojna Polski i Litwy z Zakonem Krzyzackim w latach 14091411. Malbork 2010, S. 177-187) und Sigismund von Luxemburg (Nowak, Zenon Hubert: Międzynarodowe procesy polubowne jako narzędzie polityki Zygmunta Luksemburskiego w pótnocnej i środkowowschodniej Europie 1412-1424. Toruń 1981, passim).

14 Lites ac res gestae. Tom II. Hg. von I. Zakrzewski. Poznań 1892², S. 392-395, hier S. 394: 1) die Urkunde des Königs Mindaugas aus dem Jahr 1253, in der dem Orden bestimmte Gebiete verliehen wurden und die von Papst Innozenz IV. bestätigt wurde; 2) die Urkunde des Königs Mindaugas aus dem Jahr 1255 über weitere Gebiete, welche Papst Alexander IV. bestätigte; 3) die Urkunde desselben Königs aus dem Jahr 1257 über die Belehnung des Ordens mit Samaiten; 4) die Urkunde desselben Königs aus dem Jahre 1259 über bestimmte Besitzungen in Samaiten, ausgenommen derjenigen, die der dortige Bischof hält; 5) die Urkunde Papst Innozenz' aus dem Jahre 1254 (anno pontificatus sui XI), in welcher dem Orden genannte Besitzungen (Aluchen, Kalnee, Selen, Medene, Nysegalle, Huseve) verliehen wurden; 6) die Urkunden des Königs Mindaugas aus dem Jahr 1260, der dem Orden das ganze Land Litauen verlieh; 7) die Urkunde des Papstes Alexander IV. aus dem Jahr 1260, in welcher der Ordensbruder Christian zum litauischen Bischof ernannt wurde; 8) die Urkunde des Papstes Alexander IV. vom 25. Januar 1260 (siehe Tabulae ordinis, S. 407-408, Nr. 610), in welcher alle Besitzungen und Güter, die der Orden den Händen der Heiden entreißt, bestätigt wurden; 9) zwei Urkunden Kaiser Friedrichs II., der dem Orden die Gebiete der Heiden verlieh.

15 Lites ac res gestae. Tom II, S. 394: nu see wir wol, das ir stet noch dem Lande zcu Littowen und das ir mit unserm Herren dem Kunige kriget umb dy Land zcu Litthowen, und nich umb den Cristengelowben.

16 Zur Mission Benedikts in Polen und Litauen siehe Sieradzan, Wiesław: Benedek (Benedict) Makrai as a Subarbiter in the Conflict between the Teutonic Order and its Neighbour Countries in 1412-1413. In: Arguments and Counter-Arguments, S. 157-168; ders.: Misja Benedykta Makraia w latach 1412-1413. Z dziejów pokojowych metod rozwiazywania konfliktów międzynarodowych w Europie Środkowo-Wschodniej w późnym średniowieczu. Malbork 2009. Zur Rolle König Sigismunds als Schiedsrichter im preußisch-polnischen Streit siehe Bar, Přemysl: A Tortuous Path to Reconciliation and Justice: Sigismund of Luxembourg as Arbiter in the Dispute between the Teutonic Knights and Poland (1412-1420). Zeitschrift für Ostmitteleuropa-Forschung 66, 2017, S. 3-40; vgl. Nowak, Z. H.: Internationale Schiedsprozesse als ein Werkzeug der Politik König Sigismunds in Ostmittel- und Nordeuropa 1411-1425. Blätter für deutsche Landesgeschichte N.F. 111, 1975, S. 172-188. 
quadringentesimo tredecimo, ipso die sancti Pauli Conversionis, in Cowno). ${ }^{17}$ Abgesehen von vier Urkunden des Königs Mindaugas wurde der Inhalt der päpstlichen und kaiserlichen Privilegien im Protokoll des Juristen eingefügt.

Am Anfang dieser Zusammenstellung von Privilegien stehen drei päpstliche Urkunden (Clemens IV., Alexander IV. und Innozenz IV.), die wahrscheinlich im Original vorgelegt worden waren. Bemerkenswert sind die ersten zwei Papstbullen, die wörtlich übereinstimmen. Clemens IV. wiederholt in seiner Urkunde vom 31. Mai $1265^{18}$ den Inhalt der Urkunde Papst Alexanders IV. vom 25. Januar 1260, ${ }^{19}$ in welcher die vom Orden eroberten oder noch zu erobernden heidnischen Gebiete dem Orden als allodialer Besitz übertragen und unter päpstlichen Schutz gestellt werden. ${ }^{20}$ In der dritten Papstbulle, Papst Innozenz' IV. vom 31. März 1244, die mutmaßlich ebenfalls im Original vorgelegt worden war, werden allgemein nicht näher bestimmte Gnaden, Freiheiten und Privilegien konfirmiert. ${ }^{21}$

Daneben sind vier Notariatstranssumpte im Protokoll eingefügt, die am 7. März 1352 in Riga im Auftrag des Landmeisters des Deutschen Ordens in Livland, Goswin von Herike, ausgefertigt wurden und in denen zweifelhafte Urkunden des litauischen Königs Mindaugas sowie päpstliche Konfirmationen (Alexander IV. ${ }^{22}$ und Innozenz IV. ${ }^{23}$ ) derselben Urkunden transsumiert sind. Die letzte Papstbulle in Form eines Notariatstranssumptes stammt von Papst Innozenz IV., der am 17. März 1253 alle von geistlichen und weltlichen Fürsten dem Orden gewährten Gnaden, Privilegien und Freiheiten bestätigt hatte. ${ }^{24}$

Auch der Inhalt der kaiserlichen Urkunden wurde entweder nach den Originalen oder nach Notariatstranssumpten in das Protokoll des Juristen Benedikts eingefügt:

17 Lites ac res gestae. Tom II, S. 107-135, wo die erwähnten Urkunden in extenso in das Protokoll inseriert wurden. Gemäß dem Protokoll sollen zwei originale päpstliche Bullen und 14 Notariatstranssumpte durch den Ordensprokurator vorgelegt worden sein (ebd., S. 107: [...] obtulit procurator ordinis duas bullas et XIIII instrumenta publica). Die angegebene Zahl stimmt jedoch mit folgenden Abschriften nicht überein. Zur Tätigkeit des Ordensprokurators Schuwenpflug siehe Bar, P.: Diplomacie, právo a propaganda v pozdním středověku. Polsko-litevská unie a Řád německých rytíři na kostnickém koncilu (1414-1418). Brno 2017, S. 65-71 und Borawska, Teresa: Kaspar Schuwenpflug i jego rola w procesach polsko-krzyżackich w pierwszej potowie XV wieku. Zapiski Historyczne 79/2, 2014, S. 7-28.

18 Lites ac res gestae. Tom II, S. 107-108; vgl. Tabulae ordinis, S. 417, Nr. 639.

19 Lites ac res gestae. Tom II, S. 108; vgl. Tabulae ordinis, S. 407-408, Nr. 610.

20 Lites ac res gestae. Tom II, S. 108: omnes terras, regiones, castra [...], que vos adiuti subsidio exercitus Christiani eripere poteritis de manibus paganorum, dummodo non pertineant ad aliquos Christianos vel Christiani ea non possederint a tempore cuius memoria non existit, exnunc in ius et proprietatem beati Petri suscipimus et illa sub speciali proteccione et defensione apostolice sedis [...] sanccimus ipsaque vobis et domui vestre cum omni iure et proventibus suis ac decimis exinde proventuris concedimus in perpetuum libere possidenda.

21 Lites ac res gestae. Tom II, S. 108-109; vgl. Tabulae ordinis, S. 357, Nr. 472, der aber nicht auf das Original, sondern das Transsumpt von 1412 hinweist.

22 Päpstliche Konfirmation vom 13. Juli 1257 (in Tabulae ordinis nicht gefunden) der Urkunde Mindaugas vom Oktober 1255, siehe Lites ac res gestae. Tom II, S. 111-112.

23 Päpstliche Konfirmation vom 21. August 1253 (in Tabulae ordinis nicht gefunden) der Urkunde Mindaugas" vom Oktober 1257[3?], siehe Lites ac res gestae. Tom II, S. 114-115.

24 Die Ausfertigung der Notariatstranssumpte beauftragte der Rigaer Erzbischof Johann von Wallenrode am 22. Dezember 1412, siehe ebd., S. 134-135, vgl. Tabulae ordinis, S. 372, Nr. 525. 
Am 17. Dezember 1355 bestätigt Kaiser Karl IV. dem Deutschen Orden alle seine Privilegien und Freiheiten. ${ }^{25}$

Im Juni 1245 ermächtigt Kaiser Friedrich II. den Hochmeister Heinrich von Hohenlohe auf dessen Bitte, die Länder Curland, Litauen und Semgallen mit aller Gewalt anzugreifen, und verleiht und bestätigt ihm, seinen Nachfolgern und seinem Orden alles, was er dort erobern wird. ${ }^{26}$

Am 12. Dezember 1337 überträgt Kaiser Ludwig IV. von Bayern dem Deutschen Orden das Land Litauen und investiert den Hochmeister Dietrich von Altenburg mit dem neuen Fürstentum. ${ }^{27}$

Im Mai 1245 verleiht Kaiser Friedrich II. dem Hochmeister Heinrich von Hohenlohe auf dessen Bitte das Recht Preußen, Litauen und Russland zu erobern und als Lehen mit allen Hoheitsrechten zu behalten. ${ }^{28}$

Am 17. Oktober 1383 bestätigt König Wenzel IV. die Urkunde Kaiser Karls IV. vom 17. Dezember 1355, mit der dieser wiederum die Urkunde Kaiser Friedrichs II. vom April 1221 konfirmiert. $^{29}$

Der polnischen Partei musste deutlich geworden sein, dass die Rechtsansprüche des Ordens auf Preußen, Litauen und andere Gebieten durch die vorgelegten Urkunden unzweifelhaft untermauert werden. Deswegen wurden diese Privilegien einer heftigen Kritik unterzogen.

Während des Schiedsverfahrens im Jahr 1413 erarbeitete der polnische Jurist Andrzej Łaskarzyc ein juristisches Gutachten, ${ }^{30}$ in dem er allen vom Orden vorgelegten Trans-

25 Lites ac res gestae. Tom II, S. 115-116; vgl. Tabulae ordinis, S. 247-248, Nr. 277 und J. F. Böhmer, Regesta Imperii (= RI). VIII. Regesten des Kaiserreichs unter Kaiser Karl IV 1346-1378. Aus dem Nachlasse Johann Friedrich Böhmer's hg. und ergänzt von Alfons Huber. Innsbruck 1877, Nr. 2341.

26 Lites ac res gestae. Tom II, S. 117-119, wo der Inhalt der kaiserlichen Urkunde aus dem Notariatstranssumpt von 1388 abgeschrieben wurde (ebd., S. 119: Transsuptum sub sigillo Alberti abbatis monasterii Ordinis Cristriciensis (sic) Darbatensis diocesis anno Domini millesimo CCC LXXXVIII ${ }^{\circ}$ per notarium publicum Theodricum de Leczijn Darbatensis diocesis); die Echtheit der kaiserlichen Urkunden lässt sich nicht eindeutig feststellen, vgl. RI V-1/1. Die Regesten des Kaiserreichs unter Philipp, Otto IV, Friedrich II, Heinrich (VII), Conrad, Heinrich Raspe, Wilhelm und Richard 1198-1272. Nach der Neubearbeitung und dem Nachlasse Johann Friedrich Böhmer's neu hg. und ergänzt von Julius Ficker. Innsbruck 1881, Nr. 3479.

27 Lites ac res gestae. Tom II, S. 121-123, wo der Inhalt der kaiserlichen Urkunde aus dem Notariatstranssumpt von 1393 abgeschrieben wurde; vgl. RI VII. Regesten Kaiser Ludwigs des Bayern (1314-1347) nach Archiven und Bibliotheken geordnet. Hg. von Michael Menzel. Heft 8. Die Urkunden aus den Archiven und Bibliotheken Österreichs. Bearb. von Johannes Wetzel. Köln - Weimar - Wien 2008, Nr. 379 (mit Tagesdatum 15. November).

28 Lites ac res gestae. Tom II, S. 124-127, wo der Inhalt der kaiserlichen Urkunde aus dem Notariatstranssumpt von 1389 abgeschrieben wurde (transsuptum per Iohannem clericum Warmiensis diocesis, datum Verone, actum anno millesimo CCC LXXXIX ${ }^{\circ}$ ). Es handelt sich zweifellos um eine Fälschung, für welche die oben erwähnte Urkunde vom Juni 1245 als Vorlage diente (RI V-1/1, Nr. 3479, vgl. ebd., Nr. 3474).

29 Lites ac res gestae. Tom II, S. 127-133, wo der Inhalt der königlichen Urkunde aus dem Notariatstranssumpt vom 11. Januar 1384 abgeschrieben wurde; vgl. Tabulae ordinis, S. 249, Nr. 283.

30 Dieses Gutachten wurde nachfolgend ins Protokoll Benedikts von Makra eingefügt, siehe Lites ac res gestae. Tom II, S. 294-300; zu dem Juristen und späteren Bischof von Posen Andrzej Łaskarzyc, besonders zu seiner fachlichen Tätigkeit im preußisch-polnischen Streit, siehe Ożóg, Krzysztof: Uczeni w monarchii Jadwigi Andegaweńskiej i Wtadystawa Jagietty (1384-1434). Kraków 2004, S. 186-206; ders.: Udziat Andrzeja Łaskarzyca w sprawach i sporach polsko-krzyżackich do soboru w Konstancji. In: Polska i jej sąsiedzi w późnym 
sumpten ihre Rechtskraft absprach. ${ }^{31}$ Vor allem soll es den Transsumpten an einem klaren Hinweis auf die Autorität, durch welche die Urkunden rechtmäßig transsumiert worden sein sollen, sowie auf die Anwesenheit der betreffenden Streitparteien gemangelt haben. ${ }^{32}$

Die päpstlichen Privilegien wiederum besäßen keine Rechtskraft, weil die Aussteller von den Petenten durch falsche Informationen betreffend den Gegenstand der Verfügung irregeführt worden seien. Der Orden hätte nie vorgehabt, die Heiden zum christlichen Glauben zu bekehren, sondern nur, ihnen ihr Territorium und ihr Vermögen zu entreißen. Dem polnischen Jursiten zufolgen waren die Ordensbrüder als unausgebildete Laien ohnehin unfähig, die Heiden zum Christentum zu bekehren. ${ }^{33}$

Weiter habe der Deutsche Orden wesentliche Fakten verheimlicht, nämlich dass die Heiden, also die Litauer und Samaiten, die Prediger aus den Bettelorden nie an der Verkündigung des Evangeliums gehindert hätten. Überdies besetzten die Litauer keine christlichen Länder, sondern hielten sich friedlich auf eigenem Gebiet auf. Hätte der Orden diese Informationen nicht verschwiegen, hätte er keine so verfassten päpstlichen bzw. kaiserlichen Privilegien erhalten! ${ }^{34}$

Gemäß dem polnischen Juristen bekämpfte der Deutsche Orden die Heiden und besetzte ihre Länder ohne rechtmäßigen Grund (sine iusta causa). Das rechtswidrige Verhalten des Ordens gegenüber den Heiden, mit denen in gleicher Weise wie mit dem Nächsten umgegangen werden sollen, schädige päpstliche wie kaiserliche Autorität. Das Kirchenrecht bestimme, dass niemand mit Gewalt zum Glauben gezwungen werden solle. Die Heiden sollten ausschließlich durch die Verkündigung des Wortes Gottes überzeugt werden, wozu jedoch die Ordensbrüder als Laien unfähig seien. Dementsprechend seien alle päpstlichen wie kaiserlichen Privilegien kraftlos, weil sie keine rechtliche Begründung für eine Übernahme der heidnischen Gebiete und Vermögen lieferten. ${ }^{35}$

średniowieczu. Hg. von Krzysztof Ożóg - Stanisław Szczur. Kraków 2000, S. 159-186 und Bar, P.: Diplomacie, S. 92-99, wo die Tätigkeit Andrzejs auf dem Konzil von Konstanz dargestellt wird.

31 Lites ac res gestae. Tom II, S. 294: huiusmodi litere (sint) conficte, irrite et inanes, sigillis autenticis carentes, generales et vane, non relevantes partem producentem nec probantes id, ad quod probandum inducuntur.

32 Ebd.: evidenter constat ex eisdem transsumptis, in quibus non dicitur quod transsumentes fuissent fulciti auctoritate aliqua, scilicet ordinaria vel delegata, nec decretum appositum, quod eis transsumptis fides plenaria adhiberi debet in iudiciis et extra [...] item parte non vocata nec vocatis, quorum intererat [...].

33 Ebd., S. 295: [...] quia impetrantes ut concedentem deciperent et huiusmodi literas facilius obtinerent, quedam falsa expresserunt et vera tacuerunt [...] expressunt enim falsum, quod pro fide katholica et pro convertendo ad fidem katholicam pugnassent ac infideles convertissent; quod numquam fuit nec est verum, quia nunquam aliquem ad fidem converterunt nec convertere possunt, quia sunt puri et simplices layci et non solum sacre scripture, ymmo et grammatice ignari, et semper non pro conversione infidelium, sed pro occupacione bonorum ipsorum aliquas partes infidelium invaserunt [...].

34 Ebd.: [...] in huiusmodi terris tunc infidelium, scilicet Lithwanie, Samagitarum etc. semper Christiani et viri religiosi, videlicet fratres minores, predicatores et alii semper moram traxerunt et fidem katholicam predicarunt, quam ipsi Litwani et alii protunc infideles predicare non prohibuerunt [...] nec ipsi Lithwani umquam aliquam terram Christianorum occuparunt [...] Quod si expressissent, nunquam easdem literas apostolicas, ymmo nec imperiales predictas sub eisdem tenoribus et formis obtinuissent.

35 Ebd.: [...] non est ergo phas dicere, quod Romani pontifices et imperatores katholici contra preceptum Domini ad faciendum proximo iniuriam auctoritatem prestitissent suam: constat enim de iure, quod infidelis fidei Christiane 
Andrzej Łaskarzyc bietet noch ein weiteres Argument für die Ungültigkeit der Privilegien, die lediglich bis zu Bekehrung der Heiden zum Christentum und nicht länger in Kraft bleiben dürften. Weil die Litauer, Samaiten und andere Völker durch den König von Polen und den Fürsten Witold zum rechten Glauben geführt worden seien, seien die Privilegien für den Orden völlig nutzlos. ${ }^{36}$ Die kaiserlichen Privilegien seien zudem außer Kraft, weil die Heiden, wie z. B. die Litauer, die Macht der römischen Königen und Kaiser nicht anerkennten. ${ }^{37}$

Die päpstlichen Konfirmationen von angeblichen Schenkungsurkunden des litauischen Königs Mindaugas erschienen Andrzej Łaskarzyc besonders verdächtig. Er erklärte sie aufgrund angeblich unechter Schrift und Siegel für Fälschungen ${ }^{38}$ und warf dem Orden vor, die Urkunden von Mindaugas bewusst zu unterschlagen und bei Abschluss zahlreicher Abkommen oder Waffenstillstände zwischen dem Orden und den litauischen Fürsten überhaupt nicht zu erwähnen. ${ }^{39}$

Die hier skizzierte Argumentation des polnischen Juristen wurde zum Grundstein der theoretischen Debatten und Polemiken, welche auf Initiative der polnischen Partei in den folgenden Jahren mit dem Deutschen Orden weitergeführt wurden, wie z. B. von dem jüngeren polnischen Juristen Paulus Wladimiri (Paweł Włodkowic), der sich in dieser Hinsicht besonders während des Konzils von Konstanz und in darauffolgenden

non minus est proximus noster asserendus; cum enim de iure nullus ad fidem Christianam cogendus est, quia fides ex necessitate non debet (suscipi) et servicia coacta Deo non placent ut dicunt canones sacri: non armis corporalibus ad fidem suscipiendam sunt compellendi, sed spiritualibus, scilicet gladio verbi Dei, qualem non habent Cruciferi cum sint layci illiterati. Constat igitur omnes literas tam Romanorum pontificum quam imperatorum predictas de falsitate esse suspectas, que auctoritatem patrare videntur, sine iusta causa proximum offedendi et bona sua occupandi.

36 Ebd., S. 296: [...] litere [...] Romanorum pontificum quam imperatorum [...] effectum suum tunc sortiri debent, dum et quando infideles ipsos ad fidem katholicam reducerent et imperio Romano subiugarent, et quia per alios, scilicet dominum regem Polonie et fratrem suum Witholdum Magnum principem Lithwanie in hoc preventi sunt, $[\ldots]$ et sic cessante causa, cessare debet effectus ipsarum.

37 Ebd.: [...] cum [...] Lithwania tunc in infidelitate existens imperatorem katholicum non cognoverat, patet dictum Lodwicum [Kaiser Ludwig IV. von Bayern] nullum ius in re quoad ipsam Lithwaniam habuisse, et per consequens, quod suum non fuit, donare non potuisse.

38 Ebd., S. 297: [...] sunt conficte et false, ex eo, quia nulle litere, de tempore quo dicte litere pretense donacionis dicuntur esse scripte, in partibus Litwanie similes vel sub simili sigillo sigillate reperiuntur, licet multe litere de dicto tempore $[. .$.$] in dicta terra Lithwanie [\ldots]$ reperientur date $[\ldots]$.

39 Ebd.: [...] ex eo apparent esse conficticie [sic!] et false et sunt, quia occulte tenebantur nec venerunt ad lucem per modum contradiccionis, quousque tantum tempus fluxit ipsarum literarum, quod memoria hominum ipsorum haberi non potest [...], quod licet diversi magistri Ordinis Cruciferorum cum [...] ducibus Lithwanie [...] diversos contractus et convenciones habuerunt, nunquam dictis literis usi fuerunt. Die moderne Forschung ist sich bislang nicht einig, welche der überlieferten, angeblich von König Mindaugas für den Deutschen Orden in Livland, die Rigaer Kaufleute oder den ersten litauischen Bischof Christian ausgestellten Urkunden als echt zu betrachten sind. Siehe Kętrzyński, Wojciech: O dokumentach Mendoga króla litewskiego. Kraków 1907, der fast alle Mindaugas‘ Urkunden, ausgenommen eine einzige für Bischof Christian, für Fälschungen erklärt hat. Seine Argumente sind allerdings nicht überzeugend; vgl. Klymenko, Philipp: Die Urkunden Mindowes für den livländischen Orden. Altpreussische Forschungen 6, 1929, S. 201-219 und Maleczyński, Karol: W sprawie autentyczności dokumentów Mendoga z lat 1253-1261. Ateneum Wileńskie 11, 1936, S. 1-56, der zehn Urkunden Mindaugas' unter paläografischen und diplomatischen Aspekten analysiert hat, hält sechs davon für echt; weiter siehe Kosman, Marceli: Forma umów międzynarodowych Litwy w pierwszej ćwierci XIII wieku. Przegląd Historyczny 57, 1966, S. 213-214, Anm. 4 und ders.: Dokumenty wielkiego księcia Witolda. Studia Źródłoznawcze 16, 1971, S. 142-143. 
Jahren betätigte. ${ }^{40}$ Den päpstlichen und kaiserlichen Privilegien für den Orden widmet er sich vor allem in seiner polemischen juristischen, während seines Aufenthalts in Konstanz verfassten Abhandlung Ad aperiendam. ${ }^{41}$ Ausführlich analysiert er den Inhalt einiger päpstlicher und kaiserlicher Privilegien, die schon während des Schiedsprozesses 1413 vorgelegt wurden. ${ }^{42}$ Seine mithilfe der Glossenmethode erfolgte Auslegung der jeweiligen Urkunden erbringt außer einigen Einzelheiten ${ }^{43}$ zwar nichts wesentlich Neues, doch kommt Paulus Wladimiri zu dem gleichen Urteil über die Privilegien für den Deutschen Orden wie Andrzej Łaskarzyc: [...] quod omnes litere quarumcumque libertatum, exempcionum, facultatum, confirmacionum et quecunque concessiones vel indulta qualescunque et qualiacunque a Romanis pontificibus vel ab imperatoribus sive regibus vel principibus aut personis aliis concesse vel concessa istis fratribus sub nomine vel titulo fratrum hospitalis Ierosolimitani sunt surrepticie irrite nulleque ipso iure atque false. ${ }^{44}$

Die Argumentation der polnischen Juristen scheint einen gewissen, wenn auch zeitlich begrenzten Einfluss auf die maßgebenden Persönlichkeiten während des Konstanzer Konzils gehabt zu haben. Den polnischen Gesandten gelang es nämlich, eine Urkunde von Papst Johannes XXIII. vom 17. Januar 1415 zu erhalten, in der alle bisherigen päpstlichen, kaiserlichen oder sonstigen Privilegien für den Deutschen Orden, sofern sie die Territorien, Besitzungen oder Untertanen des Königs von Polen und des Großfürsten berühren (Litauen und die russischen Gebiete sind wörtlich erwähnt), außer Rechtskraft gesetzt werden. ${ }^{45}$

In der Begründung der Papsturkunde werden historische mit rechtlichen Argumenten verflochten: Der Orden sei von den Päpsten und Kaisern damit beauftragt worden, die heidnischen Gebiete zu erobern und die Ungläubigen zum Christentum zu bekehren. Weil aber Władysław Jagiełło, Witold und ihre Untertanen den katholischen Glauben nicht aufgrund militärischen Zwangs angenommen, sondern durch den Heiligen

40 Zu ihm siehe Ożóg, K.: Uczeni, S. 92-100, wo sich weitere Literaturhinweise befinden; zu seiner Tätikgeit auf dem Konstanzer Konzil siehe Bar, P.: Diplomacie, S. 102-108.

41 Die Edition der Abhandlung siehe in Pisma wybrane Pawta Wtodkowica. Tom I. = Works of Paul Wladimiri (a selection). Vol. I. Hg. von Ludwig Ehrlich. Warszawa 1968, S. 144-271 und Pisma wybrane. Tom II. Hg. von L. Ehrlich. Warszawa 1966, S. 2-181. Weiter zu dieser Abhandlung siehe Bar, P.: Diplomacie, S. 228-229.

42 Es handelt sich hier um die Urkunden: Papst Alexanders IV. vom 25. Januar 1260 (Pisma wybrane. Tom II. Hg. von L. Ehrlich, S. 2-105); Kaiser Friedrichs II. vom Mai und Juni 1245 (ebd., S. 107-152); Kaiser Ludwigs IV. von Bayern von 1337 (ebd., S. 152-156); Kaiser Karls IV. von 1355 und König Wenzels IV. von 1383 (ebd., s. 156-157).

43 Paulus Wladimiri ging manchmal in seiner Kritik an den Ordensprivilegien noch einen Schritt weiter. Das Wesen des Ritterordens und seine Aktivitäten hätten dem in den Privilegien genannten Ordensnamen nicht mehr entsprochen, falls dies überhaupt je der Fall gewesen sei (Ordo fratrum hospitalis sancte Marie domus Theutonicorum Jerosolimitani). Die Ritterbrüder verwalteten nun nämlich kein Spital in Jerusalem mehr und betrieben auch keine Spitäler an anderen Orts, siehe Pisma wybrane. Tom II. Hg. von L. Ehrlich, S. 6: Cum autem natura istorum fratrum de Prussia non est talis quia non sunt veri hospitalarii sed sola denominacione sic dicuntur, nomen bene sibi attraxerunt sed vim nominis subtraxerunt quia hospitalibus non insistunt sed armate milicie nec morantur in hospitalibus sed in castris fortissimis. Sie verdienten eigentlich auch nicht die Bezeichnung „Orden“, sondern sollten eher als Betrüger behandelt und bestraft werden.

44 Pisma wybrane. Tom II. Hg. von L. Ehrlich, S. 9-10.

45 Monumenta medii aevi historica res gestas Poloniae illusrantia. XII. Codex epistolaris saeculi decimi quinti. Bd. II. Hg. v. Anatol Lewicki. Kraków 1891, S. 67-69, Nr. 57. 
Geist empfangen haben, bestehe keine Rechtsgrundlage mehr für den Anspruch des Ordens auf seine Oberhoheit über die genannten Herrscher und ihre Völker. Zur Begründung wird (ähnlich wie in den polnischen polemischen Schriften), eine aus dem römischen Recht stammende Schlüsselwendung angeführt, nämlich dass cum cessante causa, merito cessare debeat effectus.

Eine dauerhafte Nachwirkung dieser päpstlichen Entscheidung erscheint jedoch unwahrscheinlich, weil einige Monate später das Konzil ein Gerichtsverfahren gegen Johannes XXIII. führte, demzufolge er als Papst abgesetzt wurde. ${ }^{46}$ Später verwies keine polnische Gesandtschaft mehr auf diese Urkunde. Die Rechtskraft der päpstlichen und kaiserlichen Privilegien für den Orden scheint weiter bestanden zu haben, was die wiederholten Transsumierungen der Originale durch öffentliche Notare in den Jahren 1419 und 1421 beweisen. ${ }^{47}$

Man kann ohne Zweifel feststellen, dass die Ordensspitze von der Bedeutung und vor allem der Unanfechtbarkeit der päpstlichen und kaiserlichen Privilegien für die weitere Existenz des Ordens vom Anfang seiner Herrschaft in Preußen an völlig überzeugt war. Die polnischen Anfechtungen um die Wende des 14./15. Jahrhunderts führten den Orden jedoch allmählich zu der Erkenntnis zu, dass diese Wahrnehmung freilich nicht von allen in Europa geteilt wurde. Deswegen verfassten während des Konstanzer Konzils einige Juristen und Gelehrte im Auftrag des Ordens Gutachten, in denen das Recht des Papstes oder Kaisers auf Verleihung eines Landes der Heiden an den Orden verfochten wurde. ${ }^{48}$ Unser Blick auf die Stellung der genannten Privilegien im Leben des Ordens wäre jedoch einseitig (und damit unvollständig), wenn wir die Ordensgeschichtsschreibung des 13. bis 15. Jahrhunderts nicht in unsere Überlegungen einbeziehen würden.

\section{Die Privilegien in der Ordensgeschichtsschreibung}

Nach den Recherchen in alle relevanten historiographischen Werken, die im Auftrag des Ordens entstanden sind oder die Geschichte des Ordens behandeln, muss man überraschend feststellen, dass die Privilegien kaum erkennbare Spuren in den jeweiligen Geschichtswerken hinterlassen haben. ${ }^{49}$

46 Vgl. Boockmann, H.: Johannes Falkenberg, S. 199-200.

47 Im Zusammenhang mit dem römischen Prozess im Herbst 1421, der durch die nach dem Schiedsspruch König Sigismunds erfolgte polnische Appellation an die Kurie ausgelöst worden war, wurden 50 Transsumpte ausgefertigt, siehe Szweda, A. - Adamska, A.: Notariusz, S. 487-501.

48 Die Gelehrten betonen die unanfechtbare historische Mission des Ordens, die im Baltikum zu erfüllen sei. Sie verteidigen die Rechtmäßigkeit der päpstlichen und kaiserlichen Privilegien ohne jegliche Analyse des Urkundeninhalts, siehe Die Staatsschriften des Deutschen Ordens in Preußen im 15. Jahrhundert. Bd. 1: Die Traktate vor dem Konstanzer Konzil (1414-1418) über das Recht des Deutschen Ordens am Lande Preußen. Hg. von Erich Weise. Göttingen 1970; vgl. Srodecki, Paul: „Murus et antemurale pollens et propugnaculum tocius christianitatis“. Der Traktatenstreit zwischen dem Deutschen Orden und dem Königreich Polen auf dem Konstanzer Konzil. Schweizerische Zeitschrift für Religions- und Kulturgeschichte $=$ Revue suisse d'histoire et culturelle = Rivista svizzera di storia religiosa e culturale 109, 2015, S. 47-65 und Bar, P.: Diplomacie, S. 225-240.

49 In der Forschung wird auf einen deutlichen Unterschied zwischen der ordensinternen und ordensfremden Historiographie hingewiesen, siehe Engels, Odilo: Zur Historiographie des Deutschen Ordens im Mittel- 
Bis auf eine Ausnahme - die um 1326 entstandene lateinische Chronik von Peter von Dusburg Chronica terre Prussie. Die Chronik wurde im Auftrag des Ordens von dem Priesterbruder verfasst, der ein wichtiges Vorhaben verfolgte, nämlich die Ordensmission und -herrschaft in Preußen gegenüber dem Papst sowie dem kaiserlichen bzw. königlichen Hof zu legitimieren. ${ }^{50}$

Die ältere Forschung nahm an, dass Peter von Dusburg für seine Arbeit in großem Umfang Dokumente aus dem Ordensarchiv benutzt hatte. Spätere Studien wollten hingegen zeigen, dass vermeintliche Urkundenzitate von dem Chronisten aus anderen narrativen Quellen übernommen worden waren. ${ }^{51}$ Diese Frage kann hier nicht abschließend beantwortet werden, es sei jedoch anhand einiger Beispiele darauf verwiesen, dass diese Problematik weiterer Untersuchungen bedürfte. ${ }^{52}$

So finden wir z. B. in einem Kapitel über die Anfänge des Deutschen Ordens (De institucione ordinis domus Theutonicorum) einige relativ lange und in den Text der Chronik unauffällig eingefügte Zitate aus Urkunden Papst Honorius‘ III. Die Forschung behauptet,

alter. Archiv für Kulturgeschichte 48, 1966, S. 336-363; dagegen beleuchtet Arnold, Udo: Geschichtsschreibung im Preußenland bis zum Ausgang des 16. Jahrhunderts. Jahrbuch für die Geschichte Mittel- und Ostdeutschlands 19, 1970, S. 74-126 diese Problematik aus der Sicht der Landesgeschichte; weiter siehe Hasberg, Wolfgang: Geschichtsschreibung im Deutschen Orden. Historiographische Funktionen in fachwissenschaftlicher und fachdidaktischer Perspektive. In: Aequilibrium Mediaevale. Symposion anlässlich des 65. Geburtstages von Carl August Lückerath. Hg. von Günter Christ. Idstein 2003, S. 97-129 (nicht verfügbar); Boockmann, Hartmut: Die Geschichtsschreibung des Deutschen Ordens. Gattungsfragen und „Gebrauchssituationen”. In: Geschichtsschreibung und Geschichtsbewußtsein im späten Mittelalter. Vorträge und Forschungen 31. Sigmaringen 1987, S. 449-454 und Wenta, Jarosław: Studien über die Ordensgeschichtsschreibung am Beispiel Preußens. Toruń 2000, S. 124-182, der die Gründe für die Entstehung der Ordenshistoriographie untersucht.

50 Aus der umfangreichen Forschung zu der Chronik sei auf Pollakówna, Marzena: Kronika Piotra z Dusburga. Wrocław 1968 verwiesen; vgl. Wenta, Jarosław: Kronika Piotra z Dusburga. Szkic źródtoznawczy. Toruń 2003, dessen These über die Quellen Dusburgs Chronik jedoch nicht unumstritten sind. Der Text der Chronik wurde mehrmals ediert, siehe Petri de Dusburg Chronicon terrae Prussiae. In: Scriptores rerum Prussicarum I. Hg. v. Max Töppen. Leipzig 1861, S. 21-219; Petri de Dusburg Chronica Terre Prussie = Peter von Dusburg, Chronik des Preußenlandes. Übersetzung und erläutert von Klaus Scholz und Dieter Wojtecki. Ausgewählte Quellen zur deutschen Geschichte des Mittelalters 25. Darmstadt 1984 und Piotr z Dusburga. Kronika Ziemi Pruskiej= Petrus de Dusburgk. Chronica Terrae Prussiae. In: Monumenta Poloniae Historica N.S. 13. Hg. von Jarosław Wenta - Sławomir Wyszomirski. Kraków 2007.

51 J. Voigt, M. Töppen, M. Perlbach und M. Pollaczkówna behaupten, Peter von Dusburg habe häufig Originalurkunden aus dem Ordensarchiv in Marienburg als Vorlage benutzt. In den vermeintlichen Urkundenzitaten erkannten G. Labuda und T. Jasiński im Gegenteil eher andere narrativen Quellen, siehe Labuda, Gerard: Zu den Quellen der „Preußischen Chronik. “ In: Der Deutschordensstaat Preußen in der polnischen Geschichtsschreibung der Gegenwart. Hg. v. Udo Arnold - Marian Biskup. QSGDO 30. Marburg 1982, S. 133-164 und Jasiński, Tomasz: Jezyk dokumentów w Kronice Piotra z Dusburga. Przyczynek do poznania zaginionych zabytków historiografii pruskiej. In: Venerabiles, nobiles et honesti. Studia z dziejów społeczeństwa Polski średniowiecznej. Prace ofiarowane profesorowi Januszowi Bieniakowi w siedemdziesiątą rocznicę urodzin i czterdziestopięciolecie pracy naukowej. Toruń 1997, S. 493-505.

52 Vgl. Pollakówna, M.: Kronika, S. 143-150, die (meines Erachtens verfrüht und zu optimistisch) zu der Schlussfolgerung kommt, dass Peter von Dusburg ungehinderten Zugang zum Ordensarchiv in Marienburg gehabt und die originalen Privilegien ungehindert nutzen konnte, siehe ebd., S. 148-149: „Po sprawdzeniu sugestii Töppena i Perlbacha o wykorzystaniu dokumentów w Kronice i po dorzuceniu własnych spostrzeżeń na ten temat musimy oświadczyć, że dochodzimy do całkowitej pewności o swobodnym korzystaniu przez Dusburga z archiwum zakonnego. Wskazane wypadki utwierdzają nas w przekonaniu, że sięgał tam w kwestiach szczególnie ważnych dotyczących praw i tradycji Zakonu." 
Peter von Dusburg habe die Zitate nicht unmittelbar aus den Urkunden, sondern als Komponente seiner narrativen Quellen - Narratio de primordiis ordinis Theutonici ${ }^{53}$ und Prolog zu den Ordensstatuten ${ }^{54}$ - übernommen. In der Narratio kommt aber nur ein Zitat aus der Urkunden Honorius‘ III. vom 8. Dezember 1216 vor.

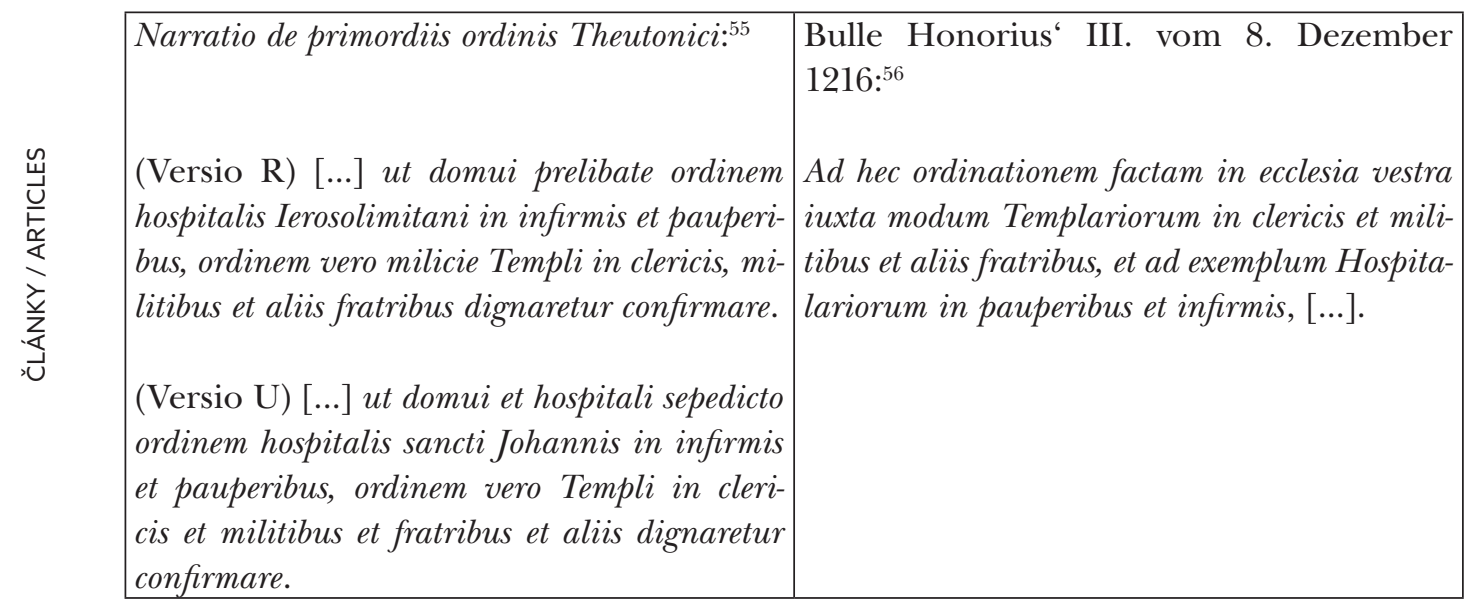

Anscheinend zitiert aber Peter von Dusburg im Kapitel De institutioni ordinis auch andere Honorius' Urkunde.

53 Arnold, Udo: De primordiis ordinis Theutonici narratio. Preußenland 4, 1966, S. 17-30 und ders.: Die Narratio de primordiis Ordinis Theutonici. Der offizielle Blick des Deutschen Ordens auf seine Anfänge. In: La mémoire des origines dans les ordres religieux-militaires au Moyen Âge. Actes des journées d'études de Göttingen $(25-26$ juin 2009) $=$ Die Erinnerung an die eigenen Ursprünge in den geistlichen Ritterorden im Mittelalter. Beiträge der Göttinger Tagung (25.-26. Juni 2009). Hg. von Philippe Josserand - Mathieu Olivier. Berlin 2012, S. 95-120.

54 Die Statuten des Deutschen Ordens nach den ältesten Handschriften. Hg. v. Max Perlbach. Halle a. S. 1890. Prolog siehe ebd., S. 22-26.

55 De primordiis ordinis Theutonici narratio. In: Scriptores rerum Prussicarum VI. Hg. von Walther Hubatsch, bearb. vnon Udo Arnold mit einer Einleitung von Erich Maschke. Frankfurt am Main 1968, S. 28; vgl. Arnold, U.: De primordiis, S. 27.

56 Tabulae ordinis, S. 272, Nr. 303; S. 276, Nr. 306. 


\begin{tabular}{|c|c|}
\hline $\begin{array}{l}\text { Peter von Dusburg, Chronik (lib. I, cap. } \\
1): 5^{57}\end{array}$ & $\begin{array}{l}\text { Bulle Honorius' III. vom 15. Dezember } \\
1220::^{58}\end{array}$ \\
\hline $\begin{array}{l}{[. . .] \text { dicit apostolus: ego plantavi, Apollo riga- }} \\
\text { vit, dominus autem incrementum dedit; ex qui- } \\
\text { bus verbis liquide licet appareat, quod neque } \\
\text { is qui plantat, neque is qui rigat, aliquid sit, } \\
\text { sed qui incrementum dat, Deus [1. Cor. 3, 7]; } \\
\text { tamen humana diligencia impensioris cure sol- } \\
\text { licitudinem debet impendere circa plantas, que } \\
\text { adhuc novelle fructus uberes afferunt et uberio- } \\
\text { res suo tempore repromittunt. [...] [...] hanc no- } \\
\text { vellam hospitalis plantacionem aliquales fruc- } \\
\text { tus honoris et honestatis tempestiva quadam } \\
\text { fecunditate producere et sperantes indubitanter, } \\
\text { quod Domino incrementum dante, expansis ra- } \\
\text { mis suis, uberrimam fructuum copiam faceret } \\
\text { in futurum [ }\end{array}$ & $\begin{array}{l}{[\ldots]} \\
\text { Etsi neque qui plantat neque qui rigat sit ali- } \\
\text { quid, se qui incrementum dat, Deus [1. Cor. 3, } \\
7], \text { humana tamen diligentia impensioris cure } \\
\text { sollicitudinem debet impendere circa plantas, } \\
\text { que adhuc novelle fructus uberes offerunt et } \\
\text { uberiores suo tempore repromittunt. Cum igi- } \\
\text { tur vestre religionis novella plantatio flores et } \\
\text { fructus odoris et honestatis tempestiva fecundi- } \\
\text { tate produxerit et Deo incrementum dante sic } \\
\text { inceperit expandare ramos suos, ut uberrima } \\
\text { fructuum copiam promittere videatur. }\end{array}$ \\
\hline
\end{tabular}

\begin{tabular}{|l|l|l|}
\hline Peter von Dusburg, Chronik (lib. I, cap. 1): ${ }^{59}$ & Bulle Honorius‘ III. vom 9. Januar 1221: ${ }^{60}$
\end{tabular}

Dignum enim erat, ut qui in operacione virtu- [...] nos volentes, ut sitis pares in assecucione tum pio vellent proposito fieri pares, in assecu- apostolici beneficii, quibus in operatione virtucione apostolici beneficii essent coequales. $\quad$ tum pio studetis proposito adequari [...].

Ein weiteres Beispiel bietet die Urkunde von Gregor IX. von 1230, in welcher der Papst den Deutschen Orden zum Kampf gegen die Prußen aufforderte. Peter von Dusburg paraphrasiert daraus nur einen Satz, dass der Deutsche Orden Rache bei den Heiden für die Beleidigung des Gekreuzigten nehmen und das den Christen gehörende Land aus den heidnischen Händen wieder zurückholen sollte.

57 Petri de Dusburg Chronicon. Hg. v. M. Töppen, S. 27.

58 Tabulae ordinis, S. 276, Nr. 306.

59 Petri de Dusburg Chronicon. Hg. v. M. Töppen, S. 27-28.

60 Tabulae ordinis, S. 281, Nr. 309. 


\begin{tabular}{|l|l|}
\hline Peter von Dusburg, Chronik (lib. II, cap. & Bulle Gregors IX. vom 18. Januar 1230: ${ }^{6}$ \\
$6{ }^{6}$ & \\
Cum autem hec destructio terre Polonie per cla- & \\
mosam insinuacionem dicti ducis ad noticiam & \\
Romane curie deveniret, sanctissimus pater et & \\
dominus Gregorius IX papa compaciens ei et & \\
precavens periculis in futurum, omnem ordina- & \\
cionem cum fratribus domus Theutonice tan- & [...] caritatem vestram monemus et hortamur \\
quam rite et racionabiliter factam in nomine & in domino, vobis et omnibus adiutoribus vestris \\
domini confirmavit, injungens dictis fratribus & in remissionem peccaminum iniungentes, qua- \\
in remissionem peccaminum, ut vindicarent in- & tinus ad eripiendum de Prutenorum manibus \\
juriam crucifixi domini et terram Cristianis de- & terram ipsam, a dextris et a sinistris Dei arma- \\
bitam recuperarent, ab infidelibus occupatam. & tura muniti, viriliter procedatis. \\
\hline
\end{tabular}

Der Chronist lässt der Paraphrasierung dieser päpstlichen Bulle unmittelbar weitere Anmerkungen folgen, die den Anschein erwecken, als ob sie ebenfalls einer päpstlichen Urkunden entstammen. Tatsächlich handelt es sich jedoch um gängige Bibelzitate, die vor allem aus dem Alten Testament stammen - 1. Buch der Makkabäer und Deuteronomium. ${ }^{63}$

Spuren der kaiserlichen Privilegien finden wir in der Chronik kaum. Lediglich im Prolog findet sich eine Anspielung auf einen Satz aus der gut bekannten Goldenen Bulle von Rimini, indem nämlich auf die vergeblichen militärischen Bemühungen um Unterwerfung der Heiden hingewiesen wird. Die Kaiserurkunde wird allerdings im Text nicht erwähnt. ${ }^{64}$

61 Petri de Dusburg Chronicon. Hg. v. M. Töppen, S. 38.

62 Preußisches Urkundenbuch (= PU). I. Politische Abteilung. Bd. I-1 (1140-1257). Hg. v. [Rudolph] Philippi in Verbindung mit [Carl Peter] Wölky. Königsberg 1882, S. 53, Nr. 72.

63 Petri de Dusburg Chronicon. Hg. v. M. Töppen, S. 38: Et exhortans [der Papst] eos [die Ordensritter] ad bellum, ait: accingimini et estote filii potentes, estote parati, ut pugnetis adversus naciones, que conveniunt disperdere nos et sancta nostra [1. Mac. 3, 58f.] [...]. Confortansque ipsos ad magnanimitatem consolatus fuit eos verbis domini, quibus usus fuit ad filios Israel, dicens: si exieris ad bellum contra hostes tuos et videris equitatus et currus et majorem, quam tu habes, adversarii multitudinem, non timebis eos, quia dominus deus tuus tecum est [Deut. 20, $1][\ldots]$.

64 Vgl. Perlbach, Max: Preussisch-polnische Studien zur Geschichte des Mittelalters. Heft II. Das Urkundenwesen Herzog Mestwin II. von Pommerellen. - Die Grosspolnischen Annalen. - Die Ältesten preussischen Annalen. - Zu Peter von Dusburg. Halle 1886, S. 106-107. 


\begin{tabular}{|c|c|}
\hline Pet & $\begin{array}{l}\text { Kaiser Friedrichs II. Goldene Bulle von Ri- } \\
\text { mini: } 66\end{array}$ \\
\hline $\begin{array}{l}{[\ldots] \text { Pruthenorum gentem sibi subdiderunt }} \\
\text { [die Ordensritter], quam eciam multi princi- } \\
\text { pes, licet sepius attemptarent, non poterant sibi } \\
\text { aliqualiter subjugare }[. . .] \text {. }\end{array}$ & $\begin{array}{l}{[. . .] \text { quemadmodum plures, multis laboribus }} \\
\text { in eodem negotio [die Heidenbekämpfung] } \\
\text { frustra temptatis, cum viderentur proficere, de- } \\
\text { fecerunt }[. . .] \text {. }\end{array}$ \\
\hline
\end{tabular}

Im Vergleich dazu weitaus mehr Raum gibt der Chronist einer Urkunde von Herzog Konrad von Masowien, in der dieser dem Deutschen das Kulmerland schenkte (der sog. Vertrag von Kruschwitz). ${ }^{67}$

Das relativ geringe Interesse des Chronisten an den päpstlichen und kaiserlichen Urkunden, die in seinem Geschichtswerk meist nur ganz allgemein angeführt werden, ${ }^{68}$ kann mit seiner theologisch begründeten Auffassung von Geschichte erklärt werden. Peter von Dusburg stellt die Ordensritter als durch Jesus Christus auserwählte Kämpfer dar, d. h. militia Dei. Ihre Legitimation komme unmittelbar von Gott, weshalb er die von den zwei höchsten abendländischen Autoritäten gewährten Privilegien nur als natürliche Anerkennung dieses Sachverhalts verstand, wie es das folgendes Zitat bezeugt: Sicque institutus et confirmatus et multis privilegiis dotatus est venerandus ille militaris ordo fratrum hospitalis sancte Marie domus Theutonicorum Jerosolimitani. Hec est vinea domini Sabaoth electa, quam tu, Jesu Christe, instituisti, fuistique dux itineris in conspectu ejus. Plantasti radices ejus et implevit terram [...]. Hec reverenda milicia non solum in terra est ab hominibus confirmata, verum eciam typo celi et terre multipharie prefigurata $[\ldots]{ }^{69}$

In den historiographischen Werken nach Peter von Dusburg sind kaum Spuren der Privilegien zu finden. In der von Johannes von Posilge - der allerdings kein Mitglied des Ordens war und dessen Werk daher nicht zur ordensinternen Historiographie gezählt werden kann - im ersten Drittel des 15. Jahrhunderts verfassten Chronik werden zwar mancherlei Urkunden, wie z. B. Friedensinstrumente, Landtagsbeschlüsse usw. ausgeschöpft, jedoch keine päpstlichen oder kaiserlichen Privilegien. ${ }^{70}$

65 Petri de Dusburg Chronicon. Hg. v. M. Töppen, S. 22.

66 PU I-1, S. 42, Nr. 56.

67 Petri de Dusburg Chronicon. Hg. v. M. Töppen, S. 36 (lib. II, cap. 5); vgl. PU I-1, S. 58-60, Nr. 78.

68 Petri de Dusburg Chronicon. Hg. v. M. Töppen, S. 29 (lib. I, cap. 1): [Zitat aus dem Prolog der Ordensstatute] Hunc ergo spiritualem ordinem ad utilitatem sancte ecclesie se generalius diffundentem congratulacionis oculo diversi summi pontifices intuentes, confirmatum plurimis privilegiis et immunitatibus et libertatibus illustrarunt; ebd., S. 31 (lib. I, cap. 5): Tempore eciam hujus fratris Hermanni [Hochmeister Hermann von Salza] meliora privilegia tam papalia quam imperialia ordinis sunt collata; ebd., S. 49 (lib. II, cap. 13): Frater Hermannus de Salcza, magister generalis, vir providus et in omnibus circumspectus, medio tempore, quo supradicta agerentur, accessit ad dominum papam et inter alias peticiones petivit et obtinuit crucem predicari in regnis et provinciis a sede apostolica tunc deputatis in subsidium terre Prussie deditque idem papa et postea Innocencius papa IIII peregrinis Prussiam et Lyvoniam visitantibus privilegia et indulgencias, sicut euntibus Ierosolimam conceduntur.

69 Ebd., S. 28 (lib. I, cap. 1). Auf eine enge Verknüpfung der Heils- mit der Ordensgeschichte in der Ordenshistoriographie weist Engels, O.: Zur Historiographie, S. 349 hin.

70 Johanns von Posilge, Officials von Pomesanien, Chronik des Landes Preussen zugleich mit den auf Preussen 


\section{Spätmittelalterliche Kopialbücher des Deutschen Ordens und Privilegientranssumpte}

Die Kopialüberlieferung der päpstlichen und kaiserlichen Privilegien ist mit der Geschichte des Ordensarchivs eng verbunden. Die Erforschung seiner Geschichte ist aber bedauerlicherweise immer noch sehr lückenhaft, und es fehlt eine grundlegende Monographie. ${ }^{71}$ Das Gleiche gilt auch für die Untersuchung der Ordenskopialbücher, die in verschiedenen Ordensarchiven überliefert sind. Da an dieser Stelle keine vollständige Durchsicht aller Kopialbücher aus den Ordensarchiven geleistet werden kann, sei auf einige aussagekräftige Beispiele aus dem Zentralarchiv des Deutschen Ordens in Wien verwiesen. Meine Schlussfolgerungen stimmen teilweise mit denjenigen Bernhart Jähnigs überein, die dieser aus der Untersuchung der Übersetzungen der lateinischen Privilegien in den in Berlin aufbewahrten Ordensfolianten gezogen hat. ${ }^{72}$ Dies betrifft auch den aus dem 15. Jahrhundert stammenden Ordensfolianten Nr. 70, der zahlreiche mit Randbemerkungen und Hinweisen versehene Abschriften und Regesten päpstlicher und kaiserlicher Privilegien umfasst. ${ }^{73}$

Es ist anzunehmen, dass die Privilegien nicht nur am Sitz der Ordensleitung, sondern auch an zahlreichen Ordensniederlassungen aufbewahrt wurden, auch wenn sie nicht

bezüglichen Abschnitten aus der Chronik Detmar's von Lübeck. In: Scriptores rerum Prussicarum III. Hg. v. Ernst Strehlke. Leipzig 1866, S. 13-57, 79-397.

71 Es sei hier auf die immer noch unbefriedigende Erforschung der Geschichte des Hochmeisterarchivs im Mittelalter verwiesen, von den Archiven bzw. der Aufbewahrung der Urkunden in einzelnen Ordenshäusern (Kommenden) ganz zu schweigen, vgl. Glauert, Mario: Von Akkon bis Königsberg: Das Archiv der Hochmeister des Deutschen Ordens. In: Preussens erstes Provinzialarchiv: Zur Erinnerung an die Gründung des Staatsarchivs Königsberg vor 200 Jahren. Hg. von Bernhart Jähnig - Jürgen Kloosterhuis. Tagungsberichte der Historischen Kommission für ost- und westpreußische Landesforschung 20. Marburg 2006, S. 27-52; Die Urkunden des Deutschordens-Zentralarchivs in Wien. Regesten nach dem Manuskript von Marian Tumler hg. von Udo Arnold. Teilband I: 1122-1313. QSGDO 11/I. Marburg 2006, wo die Geschichte des Ordenszentralarchivs in Wien kurzgefasst wird. Weiter siehe den Tagungsband: Das „Virtuelle Archiv des Deutschen Ordens. "Beiträge einer internationale Tagung im Staatsarchiv Ludwigsburg am 11. und 12. April 2013. Hg. von Maria Magdalena Rückert. Stuttgart 2014 und Bayard, Frank: Das Deutschordens-Zentralarchiv in Wien. In: Österreichische Archive. Geschichte und Gegenwart, Brno 2019 (im Druck). Weil das Hochmeisterarchiv eng mit dessen Kanzlei verknüpft war, sind auch zwei Sammelbände über die Ordenskanzleien von gewissem Nutzen: Kancelarie krzyżackie. Stan badań i perspektywy badawcze. Materiaty z międzynarodowej konferencji naukowej Malbork 18-19 X 2001. Hg. von Janusz Trupinda. Malbork 2002 und Kancelaria wielkich mistrzów i polska kancelaria królewska w XV wieku. Materiaty z międzynarodowej konferencji naukowej Malbork 2-3 IX 2004. Hg. von Janusz Trupinda. Malbork 2006. Eine Übersicht über die Geschichte der Ordenskanzlei bietet Trupinda, Janusz: Zarys dyplomatyki krzyżackiej w Prusach. In: Dyplomatyka staropolska. Hg. von Tomasz Jurek. Warszawa 2015, S. 518-528, wo weitere Literaturhinweise zu finden sind.

72 Jähnig, Bernhart: Die Übersetzung lateinischer Urkunden ins Deutsche durch die Hochmeisterkanzlei - Unter besonderer Berücksichtigung der Goldenen Bulle von Rimini. In: Die Rolle der Schriftlichkeit in den geistlichen Ritterorden des Mittelalters: Innere Organistaion, Sozialstruktur, Politik. Hg. von Roman Czaja - Jürgen Sarnowsky. Ordines Militares 15. Toruń 2009, S. 133-166.

73 Die Hinweise beziehen sich auf den Aufbewahrungsort der jeweiligen Urkunden, die sich überwiegend im Hochmeisterarchiv befanden, siehe Gouguenheim, Sylvain: Das Cartular von Ptock: einige Bemerkungen zur Schriftlichkeit, Archivierung und Geschichte des Deutschen Ordens in der Mitte des 15. Jahrhunderts. In: ebd,, S. 99-119. 
speziell diese Orte betrafen. Bei vielen Originalen muss man auch mit Mehrfachüberlieferung rechnen. Relativ früh (am Ende des 13. Jahrhunderts) entstanden abschriftliche Zusammenstellungen der wichtigsten Urkunden. Weitere Fragen sind jedoch nach wie vor offen, wie z. B., wann und zu welchem Zweck die Originale oder die Abschriften benötigt wurden. Aufgrund der bewegten Geschichte des Ordens gibt es vielfältige Möglichkeiten.

Als Beispiel für Beliebtheit und Ausmaß solcher Privilegiensammlungen können zwei im Zentralarchiv des Deutschen Ordens (DOZA) in Wien aufbewahrte Pergament-Handschriften aus dem 13. bzw. 15. Jahrhundert dienen. ${ }^{74}$ Inhaltlich sind beide Handschriften sehr ähnlich. Sie beinhalten eine aus dem 13. Jahrhundert stammende Zusammenstellung von Privilegien, vorwiegend von Päpsten (von den kaiserlichen Privilegien sind nur einige von Kaiser Friedrich II. zu finden). Jede Abschrift (oder jeder Eintrag) hat eine eigene Rubrik und beginnt mit einer farbigen Initiale. Die jüngere Handschrift (Hds. 288) unterscheidet sich von der älteren durch zwei Merkmale: eine üppigere Dekoration sowie Randbemerkungen, die auf den jeweiligen Papst als Aussteller des Privilegs sowie bestimmte Ortsnamen eines Ordenshauses verweisen. Es ist anzunehmen, dass es sich um den Aufbewahrungsort der jeweiligen Privilegien handelt. Am häufigsten wird der Ort „Mergentheim“ genannt. Auffällig ist auch, dass es sich bei den Ortsangaben ausschließlich um im Reich gelegene Kommenden handelt, woraus jedoch sicher nicht der Schluss gezogen werden kann, dass die Handschrift außerhalb Preußen entstanden sein muss. ${ }^{75}$ Bei beiden Handschriften ist heute kein mittelalterlicher Besitzer bekannt. ${ }^{76}$

Eindeutige Motive, die zur Entstehung solcher Privilegiensammlungen geführt haben könnten, sind nicht einfach zu ermitteln. Man darf wohl davon ausgehen, dass vor allem praktische Aspekte dahinter standen. Der Ordensfoliant 67 z. B., der heute im Geheimen Staatsarchiv Preußischer Kulturbesitz in Berlin aufbewahrt wird, soll zur Zeit des Hochmeisters Michael Küchmeister im Zusammenhang mit der Auseinandersetzung mit Polen-Litauen während des Konstanzer Konzils (1414-1418) entstanden sein. ${ }^{77}$ Ähnlich ließ der Hochmeister Paul von Rusdorf in den 20er und 30er Jahre des 15. Jahrhunderts die wichtigsten Privilegien des Ordens aus der Zeit vor der Übersiedlung des Hochmeisters nach Marienburg für die dortige Zentrale in Kopiaren zusammenfassen. Dahinter darf man wohl den praktischen Gedanken vermuten, bestimmte allgemeine Privilegien vor Ort zur Hand zu haben.

Der nochmalige Blick auf einige Handschriften im Zentralarchiv des Deutschen Ordens in Wien, die Abschriften päpstlicher oder kaiserlicher Privilegien beinhalten, legt die Vermutung nahe, dass für den Deutschen Orden offensichtlich zwei Privilegiensammlungen eine wesentliche Rolle gespielt haben. Beide gehen auf eine Initiative des Deutschmeisters Eberhard von Seinsheim (1420-1443) zurück.

74 DOZA Wien, Handschriftensammlung, Hds. 301; und Hds. 288 (keine Foliierung).

75 Z. B. siehe ebd., Nr. 84: Gregorius in Leodio et in Marphurg et in Prage.

76 Der älteste Besitzvermerk in Hds. 288 lautet: Ballivia Confluentina 1525.

77 Jähnig, B.: Die Übersetzung, S. 154. 
Am 12. März 1427 beauftragte Sigismund von Luxemburg den Pfalzgrafen Ludwig von Bayern auf Bitten Eberhards von Seinsheim, die im Besitz des Ordens befindlichen kaiserlichen Privilegien transsumieren zu lassen. ${ }^{78}$ Der Pfalzgraf führte den königlichen Auftrag erst ein Jahr später aus (21. März 1428), als er die Privilegien von den Kaisern bzw. Königen Friedrich II., Konrad IV., Richard von Cornwall, Rudolf von Habsburg, Adolf von Nassau, Albrecht von Habsburg, Heinrich VII., Ludwig IV. von Bayern und Karl IV. transsumieren ließ. ${ }^{79}$

Im Jahr 1434 ersuchte Eberhard von Seinsheim den Kardinaldiakon und päpstlichen Legaten Giuliano Cesarini, 87 bestimmte päpstliche Privilegien für den Deutschen Orden transsumieren zu lassen. ${ }^{80}$ Als Kardinal Cesarini das Konzil von Basel verließ und zu Papst Eugen IV. übertrat (1437), erneuerte der Deutschmeister seine Forderung gegenüber dem Konzil nach einer erneuten Transsumierung der oben genannten päpstlichen Privilegien (24. April 1439). Obwohl es sich - soweit durch den Vergleich der inserierten Urkunden mit der Edition Strehlke Tabulae ordinis ersichtlich - zumeist um allgemeine päpstliche Privilegien handelt, wird in der Urkunde des Konzils von Basel betont, dass die inserierten Bullen dem Deutschen Orden im Reich und Italien gewährt worden seien (literas $[\ldots]$ hospitali per Alamaniam et Italiam concessas). ${ }^{81}$

Es ist durchaus nicht zufällig, dass die Entstehung der Privilegiensammlung in die Amtszeit Eberhards von Seinsheim fällt. Die Auseinandersetzungen zwischen dem Deutschmeister und dem Hochmeister, Paul von Rusdorf, spitzten sich gerade damals sehr scharf zu. Eberhard von Seinsheim ließ die so genannten „Orselnschen Statuten“ verfassen, die wesentliche Befugnisse des Hochmeisters einzuschränken versuchten. Paul von Rusdorf bezeichnete diese „Statuten“ als Fälschung, trotzdem ließ sie sich Eberhard von Seinsheim vom Konzil von Basel 1437 bestätigen. Der Hochmeister enthob den Deutschmeister sogar - obschon vergeblich - seines Amtes. ${ }^{82}$ In diesem Zusammenhang ist zu erwähnen, dass Eberhard von Seinsheim mit der Transsumierung der päpstlichen Privilegien bereits Anfang der zwanziger Jahre begann. ${ }^{83}$ Dieses Vorhaben des Deutschmeisters darf man wohl auch als ein Zeichen seines Bestrebens nach Autonomie des Ordens im Reich gegenüber dem Hochmeister in Preußen verstehen. ${ }^{84}$

Die zwei oben beschriebenen Sammlungen päpstlicher bzw. kaiserlicher Privilegien

78 RI XI. Die Urkunden Kaiser Sigmunds 1410-1437. 2. 1425-1437. Hg. von Wilhelm Altmann. Innsbruck 1897-1900, Nr. 6831.

79 Siehe Anm. 86.

8026 Bullen von Honorius III., 13 von Gregor IX., 6 von Innozenz IV., 15 von Alexander IV., 1 von Clemens IV., 4 von Urban IV., 2 von Nikolaus IV., 6 von Bonifaz IX., 2 vom Konzil von Konstanz, 10 von Martin V. und 2 von Eugen IV., siehe Abschrift des Notariatsinstruments aus dem 15. Jahrhundert in DOZA Wien, Handschriftensammlung, Hds. 157, ohne Foliierung.

81 DOZA Wien, Handschriftensammlung, Hds. 478, fol. 1r.

82 Militzer, Klaus: Die Geschichte des Deutschen Ordens. Stuttgart 2012², S. 259-265.

83 Siehe die originalen Notariatsinstrumente in DOZA Wien, Urkunden, Nr. 3116, Nr. 3118, Nr. 3123 und Nr. 3158.

84 Vgl. Lückerath, Carl August: Deutschmeister Eberhard von Saunsheim - Widersacher des Hochmeistertums? Zeitschrift für Ostforschung 18, 1969, S. 270-287 und ders., Paul von Rusdorf. Hochmeister des Deutschen Ordens 1422-1441. QSGDO 15. Bad Godesberg 1969, S. 174-176. 
erfuhren dann im Orden eine gewisse Popularität. Zu diesem Schluss veranlassen uns einige von öffentlichen Notaren im Auftrag von Haus- oder Landeskomturen ausgefertigte Notariatsinstrumente sowie deren zahlreichen neuzeitlichen Abschriften, die heute im DOZA in Wien überliefert sind.

Am 15. Februar 1470 ließ ein Hauskomtur (der Name wird nicht genannt) aus Sachsenhausen bei Frankfurt (heute Stadtteil von Frankfurt am Main) beide Sammlungen (sowohl die päpstliche als auch die kaiserliche) durch einen öffentlichen Notar transsumieren. ${ }^{85}$

Am 22. Juli 1445 ließ der Landkomtur der Ballei Utrecht, Mathias van der Straten, sowohl einige päpstliche Originalurkunden als auch die oben erwähnte Urkunde des päpstlichen Legaten Giuliano Cesarini von 1434 transsumieren, die alle der Ordenspriester Nikolaus von Dessener, der Prokurator des Landkomturs, vorgelegt hatte. ${ }^{86}$

\section{Schlussfolgerungen und Forschungsperspektive}

Die Bedeutung der päpstlichen und kaiserlichen Privilegien als Rechtsmittel für den Deutschen Orden wurde mehrfach von der Forschung erkannt und betont. So wurden sie auch von den Zeitgenossen wahrgenommen. Dass die schiere Existenz des Ordens von der Rechtskraft bestimmter Privilegien abhing, begriffen die Ordensbrüder allerdings erst wirklich, als die polnischen Juristen versuchten, die Rechtmäßigkeit päpstlicher bzw. kaiserlicher Urkunden für den Orden anzufechten. In diesem Zusammenhang ist auffällig, dass Kopialbücher und Privilegientranssumpte vor allem in zwei Zeiträumen der Ordensgeschichte entstanden sind: erstens um die Wende des 13./14. Jahrhunderts, und zweitens in der ersten Hälfte des 15. Jahrhunderts, also in Zeiten, in denen die Existenz des Ordens gefährdet war.

85 Siehe Abschrift aus dem 16. Jahrhundert in DOZA Wien, Handschriftensammlung, Hds. 200, ohne Foliierung; zwei Abschriften desselben Notariatsinstruments aus dem 16. bzw. 18. Jahrhundert, die aber lediglich die kaiserlichen Privilegien umfassen, d. h. die Urkunde vom 21. März 1428 (siehe oben), siehe in DOZA Wien, Handschriftensammlung, Hds. 138 und Hds. 108.

86 DOZA Wien, Handschriftensammlung, Hds. 163, fol. 3r: [...] personaliter [...] Nicholaus de Dessener presbiter professus domus beate Marie Theutonicorum Jerosolomitani de Iunctis [Utrecht] opidi Traiectensis supra Mosam [Maastricht] Leodiensis [Lüttich] diocesis ac investitus ecclesie parochialis sancti Andree Leodiensis procurator et procuratorio nomine, prout asseruit, venerabilis et religiosi viri domini Mathie van der Straten provincialis ballivie de Iunctis dicti ordinis habens et tenens in suis manibus plures et diversas litteras apostolicas de et super diversis materiis indultis et privilegiis a sancta sede apostolica a diversis ecclesie Romane pontificibus impetratas predictum ordinem concernentes veris bullis plumbeis more Romane curie in filis sericis rubei croceique coloris impendens bullatas necnon quoddam publicum certi voluminis seu registri transsumpti cum decreto de diversis litteris originalibus apostolicis et privilegiis predictum ordinem eciam concernentibus in huiusmodi volumine insertis inscriptum [...] dominum Julianum [...] sancti Angeli sancte Romane ecclesie dyaconum cardinalem in Germania apostolice sedis legatum in Basilea confectum [...]. Die Ausfertigung des Notariatsinstruments wird mit praktischen Argumenten begründet, gemäß denen die Privilegien allgemein sehr schwer zugänglich seien, siehe ebd.: propter varia viarum discrimina locorumque distantias lites et guerras dominorum et alia impedimenta et pericula ipsas litteras et transsumptum de loco ad locum pro utilitate ordinis et domorum transmitti et deduci ac deferre sine gravi periculo non posset nec auderet. 
Im Gegensatz dazu scheint die Ordenshistoriographie, die zur Illustration des Ordensselbstverständnisses als geistlich-ritterliche Korporation von großer Bedeutung ist, sehr bescheidenen Gebrauch von den Privilegien zu machen. Diesen Befund kann man wohl dadurch erklären, dass Ethos und Identität der Ordensbrüder unmittelbar von Gott abgeleitet wurden. Päpstliche oder kaiserliche Förderung wurden demzufolge nur als natürliche Leistung angesehen. ${ }^{87}$

Aus der Überlieferungsweise der päpstlichen und kaiserlichen Privilegien ergeben sich (allerdings aufgrund sehr unvollständiger Archivrecherchen) drei unterschiedlichen Arten der Sammlungen. Auf der Grundlage der bisher erfolgten, allerdings noch nicht vollständigen Archivrecherchen können die päpstlichen und kaiserlichen Privilegien nach Art ihrer Überlieferung vorerst in drei Sammlungen unterschieden werden: Die Zusammenstellung (1) der ausschließlich aus dem 13. Jahrhundert stammenden Privilegien, (2) aller wichtigsten päpstlichen sowie kaiserlichen Privilegien vom 13. bis zum 15. Jahrhundert und (3) der in einzelnen Kommenden- oder Balleiarchiven aufbewahrten Privilegien. Allerdings muss dabei beachtet werden, dass sich (hinsichtlich der Intention der Sammlungen?) memoriale von rechtlichen Aspekten nicht immer eindeutig abgrenzen lassen. Es bleibt die Aufgabe weiterer Forschungen, das Augenmerk vor allem auf die Kopialüberlieferung zu richten. Schwerpunkte sollten dabei auf eine Übersicht über die erhaltenen Kopialbücher bzw. Privilegientranssumpte, die Untersuchung ihres Inhaltes sowie die hilfswissenschaftliche und historische Analyse ihres Entstehungszusammenhangs gelegt werden.

\section{Papežská a císařská privilegia pro řád německých rytířů v Prusku mezi právem a pamětí. Úvod $k$ tématu}

Význam papežských a císařských privilegií pro řád německých rytîrů je v bádání zdůrazňován opakovaně, přičemž analýza těchto listin bývá většinou prováděna z hlediska diplomatického nebo právně-historického. Poprvé je v této studii tematizován vztah mezi právním a memoriálním rozměrem příslušných privilegií. Autor promýšlí tř̌i aspekty, které se zdají být klíčové k osvětlení dané problematiky.

První se týká období politických a právních sporů s polsko-litevskou unií po roce 1386. Čím více se polští juristé (Andrzej Łaskarzyc, Pavel Vlodkovic) snažili vědecky zpochybnit právoplatnost oněch privilegií, tím více si vedení řádu uvědomovalo nejen jejich právní význam, nýbrž i jako historickou pamět o poslání řádu.

Na druhou stranu papežská ani císařská privilegia nebyla př́liš využívána ve středověkém řádovém dějepisectví (snad s výjimkou kroniky Petra z Dusburgu, jehož text je v této souvislosti podroben detailnější analýze), které je ovšem považovalo za samozřejmou součást řádových dějin. Tuto skutečnost lze vysvětlit sebepojetím řádových rytírủ jako Božích bojovníků, jejichž původ a poslání byly odvozovány přímo od Ježíše Krista.

87 Vgl. Wüst, Marcus: Studien zum Selbstverständnis des Deutschen Ordens im Mittelalter. QSGDO 73. Weimar 2013. 
Třetí důležitý aspekt představují kopiáře, které jsou v různé podobě dochovány už od konce 13. století, a hromadné konfirmace papežských a císařských privilegií. Na základě neúplných archivních rešerší lze přesto rozlišit tři druhy sbírek papežských a císařských listin: 1) soubor privilegií výlučně ze 13. století; 2) z období od 13. do 15. století nebo 3) uložených v př́slušné řádové komendě či bailii. Z hlediska záměrů sestavovatelů oněch sbírek je výzvou pro další výzkum vymezení hranice mezi právními a memoriálními motivacemi při jejich vzniku. 
